\title{
Erratum to: Effects of Castration and Testosterone Replacement on the Antioxidant Defense System in Rat Left Ventricle
}

\author{
B. Kłapcińska • S. Jagsz • E. Sadowska-Krępa • \\ Jan Górski $\cdot$ K. Kempa $\cdot$ J. Langfort
}

Published online: 26 February 2013

(C) The Physiological Society of Japan and Springer Japan 2013

Erratum to: J Physiol Sci (2008) 58:173-177

DOI 10.2170/physiolsci.RP002208

The authors are sorry to report that in the above mentioned article there is an error in the units used to describe the level of TBA-reactive substances (MDA), which should have been expressed as $\mathrm{nmol} / \mathrm{g}_{\mathrm{wet}} \mathrm{wt}$, and not as $\mu \mathrm{mol} / \mathrm{g}_{\text {wet wt }}$. This correction does not alter any of the conclusions reached in this study. The authors apologize for the error and any confusion it may have caused.

The online version of the original article can be found under doi:http://dx.doi.org/10.2170/physiolsci.RP002208.

B. Kłapcińska $(\bowtie) \cdot$ S. Jagsz · E. Sadowska-Krępa ·

K. Kempa $\cdot$ J. Langfort

Department of Physiological and Medical Sciences, Academy

of Physical Education, 72A Mikolowska Str, 40-065 Katowice,

Poland

e-mail: b.klapcinska@awf.katowice.pl

J. Górski

Department of Physiology, Medical University of Bialystok,

2c Mickiewicza Str., Bialystok, Poland

J. Langfort

Department of Pharmacology, Polish Academy of Sciences

Medical Research Center, 5 Pawinskiego Str., 02-106 Warsaw,

Poland 